\title{
Strombolian explosions \\ 1. A large bubble breaking at the surface of a lava column as a source of sound
}

\author{
S. Vergniolle ${ }^{1}$ \\ Institute of Theoretical Geophysics, University of Cambridge, Cambridge, England \\ G. Brandeis ${ }^{2}$ \\ Laboratoire de Dynamique des Systèmes Géologiques, Institut de Physique du Globe de Paris
}

\begin{abstract}
Strombolian activity consists of a series of explosions caused by the breaking of large overpressurized bubbles at the surface of the magma column. Acoustic pressure has been measured for 36 explosions at Stromboli. We propose that sound is generated by the vibration of the bubble before it bursts. Oscillations are driven by an initial overpressure inside the bubble, assumed to be initially at rest, just below the magma-air interface. Inertia effects cause the bubble to overshoot its equilibrium radius. Then the bubble becomes underpressurized and contracts because of gas compressibility. These oscillations are only slightly damped by viscous effects in the magma layer above the bubble. The bubble cannot complete more than one cycle of vibration because of instabilities developing on the magma layer that lead to its breaking, near the minimum radius. Assuming a simple geometry, we model this vibration and constrain the radius and length of the bubble and the initial overpressure by fitting a synthetic waveform to the measured acoustic pressure. The fit between synthetic and observed waveforms is very good, both for frequency, $\approx 60 \mathrm{rad} \mathrm{s}^{-1}$, and amplitude. The initial bubble radius is $\approx 1$ $\mathrm{m}$, and the length varies between several and a few tens of meters. From the initial overpressure, approximately $10^{5} \mathrm{~Pa}$, we calculate the maximum radial velocity of ejecta, $\approx 30 \mathrm{~m} \mathrm{~s}^{-1}$. The generally good agreement between data and predictions of our model leads us to suggest that acoustic measurements are a powerful tool for the understanding of eruption dynamics.
\end{abstract}

\section{Introduction}

Volcanic eruptions present different regimes, which can be understood and classified in the framework of a two-phase flow [Vergniolle and Jaupart, 1986]. In basalts, the differential motion of the gas with respect to the liquid produces either an annular flow in Hawaiian fire fountains or a slug flow in Strombolian explosions [Vergniolle and Jaupart, 1986]. The gas, formed

\footnotetext{
${ }^{1}$ Now at Laboratoire de Dynamique des Systèmes Géologiques, Institut de Physique du Globe de Paris.

${ }^{2}$ Now at UMR 5562 CNRS, Groupe de Recherches de Géodésie Spatiale, Observatoire Midi-Pyrénées, Toulouse, France.

Copyright 1996 by the American Geophysical Union.

Paper number 96JB01178.

0148-0227/96/96 JB-01178\$09.00
}

at depth, carries physical information about the dynamics of Strombolian activity, which may lead to a better understanding of the system.

Stromboli volcano has been in a quasi-permanent state of eruptive activity for more than 2000 years. Activity of Stromboli is characterized by a series of explosions, occurring with a regular intermittency, from $10 \mathrm{~min}$ to 1 hour. The height reached by ejecta above the vent varies from a few meters to a hundred meters, with velocities between 50 and $100 \mathrm{~m} \mathrm{~s}^{-1}$ [Chouet et al., 1974; Weill et al., 1992]. Their origin lies in the breaking of a metric, overpressurized bubble at the surface of the magma column (Figure 1) [Blackburn et al., 1976; Wilson, 1980; Braun and Ripepe, 1993]. Such gas pockets, almost as large as the volcanic conduit, are formed intermittently at depth in a shallow magma chamber by coalescence of a foam layer [Jaupart and Vergniolle, 1988, 1989; Vergniolle and Jaupart, 1990].

Large bubbles, over a meter in diameter, have been studied when formed by underwater explosions [Cole, 1948; Davies and Taylor, 1950; Taylor, 1963; Taylor and 

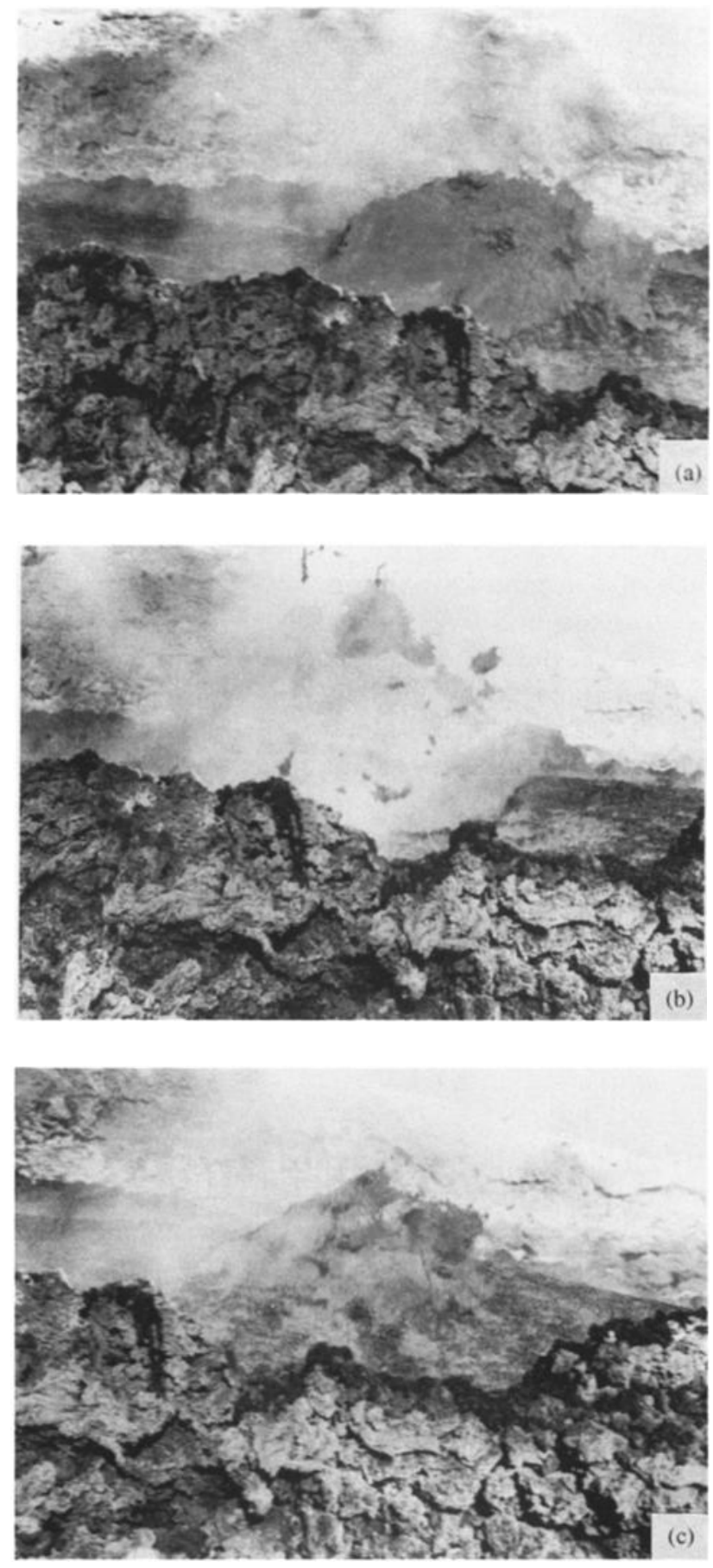

Figure 1. Photographs of a bubble bursting on a lava flow at Etna (Italy) in May 1983 (courtesy of J.-L. Cheminée). (a) The bubble protrudes at the lava surface showing a hemispherical cap. (b) When the bubble bursts, the thickness of the magma above the bubble is smaller than the bubble size and of the order of the size of ejecta. (c) After bursting, the lava surface becomes flat again.

Davies, 1963]. The violent formation of the gas pocket under rapid chemical reaction sends a shock wave into the surrounding water, followed by strong oscillations of the newly formed bubble [Cole, 1948; Leighton, 1994]. Small bubbles in an infinite liquid have been also ex- tensively studied, either in engineering [Boulton-Stone and Blake, 1993; Leighton, 1994] or in the ocean [Spiel, 1992]. In the ocean, small bubbles (below $2 \mathrm{~mm}$ ), formed by breaking gravity waves at the surface of the water [Thorpe, 1980; Spiel, 1992], produce significant levels of sound in the ocean [Longuet-Higgins, 1990]. The bursting of gas bubbles at the surface of a liquid has been studied for small bubbles, and these fluid dynamic studies were recently combined with acoustic measurements [Spiel, 1992]. Similarly, we have carried out acoustic measurements at Stromboli volcano in order to understand the detailed processes occurring when a large bubble, formed in a highly viscous fluid, breaks at an air-liquid interface.

At Stromboli, visual observations of the western vent show that sound and ejecta are produced simultaneously when bubbles break at the surface of the lava between explosions ( $P$. Allard, personal communication, 1993), linking aerial explosions to the breaking of large overpressurized bubbles. Bubbles rising in a tube slightly larger than the bubble size correspond to slug flow, which has been widely studied in chemical engineering [Wallis, 1969; Butterworth and Hewitt, 1977; Kay and Nedderman, 1985]. Most previous studies have been applied to small tubes in which capillary effects are important or to fluid liquids, with viscosities less than 1 $\mathrm{Pa}$ s. We can compare Stromboli to a large-scale experiment in which the tube has a radius of $\approx 1 \mathrm{~m}$, a length above a few hundred of meters [Giberti et al., 1992], and a viscosity above $100 \mathrm{~Pa}$ s. In these conditions, the Reynolds number of the bubble, around 80 , indicates that the viscosity of the magma cannot be neglected, and the bubble rise speed, independent of the bubble length, is around $1.6 \mathrm{~m} \mathrm{~s}^{-1}$ [Wallis, 1969; Butterworth and Hewitt, 1977]. Furthermore, in chemical engineering, studies on large bubbles neglect the influence of any air-liquid interface on the bubble behavior.

Previous studies of acoustics on volcanoes are sparse [Richards, 1963; Woulff and McGetchin, 1976]. Gas velocities around $100 \mathrm{~m} \mathrm{~s}^{-1}$ in Strombolian activity led Woulff and McGetchin [1976] to suggest, without quantitative acoustic measurements, that the source of the sound generated by Strombolian explosions is a dipole. Recent acoustic measurements [Vergniolle and Brandeis, 1994] including low frequencies, between $4 \mathrm{~Hz}$ and a few kilohertz, showed that the source is a monopole and led us to suggest that the sound is produced by the vibration of a large bubble due to a sudden overpressure at the exit of the vent. In an alternate model, Buckingham and Garcés [1996] suggest that the source of sound at Stromboli is explosive and embodied deep in the magma column.

Bubble oscillations have long been recognized to be a source of sound [Batchelor, 1967; Leighton, 1994]. Ascending bubbles adjust their size to the decreasing pressure. In a magma, viscous forces significantly delay the growth to equilibrium, and overpressure can build up inside the bubble [Chouet et al., 1974; Blackburn 
et al., 1976]. With such a mechanism, the velocity of ejecta is related to overpressure, estimated around 600 $\mathrm{Pa}$ at Stromboli. However, it breaks down for larger overpressures, as existing at Heimaey $\left(2.5 \times 10^{4} \mathrm{~Pa}\right)$, because it implies unreasonably large velocity for the bubble growth [Blackburn et al., 1976].

In a previous study [Vergniolle and Brandeis, 1994], based on small oscillations, the measured frequency was related to the radius of the bubble, around $1 \mathrm{~m}$. In this paper, we develop the complete set of equations for the general case and express the amplitude of oscillations as a function of the bubble overpressure. Then we show how to estimate the size of the bubble, its initial overpressure, and the velocity of ejecta from the measured intensity of acoustic pressure. We also discuss the mechanisms by which a large overpressurized bubble can break at the surface of a lava column. Finally, we present alternate models and compare the results.

\section{Characteristics of Stromboli}

Although Stromboli has two active craters, we focus on the eastern one, which undergoes one explosion per hour on the average. Four vents have been recognized inside the eastern crater in September 1971. The only observed opening is circular, roughly $0.5 \mathrm{~m}$ in diameter [Chouet et al., 1974]. There are no data for the volcanic conduit diameter at depth. Giberti et al. [1992] have estimated the chamber depth to be a few hundreds of meters. However, the exact value of these two parameters are not crucial for the reasoning, since our study is centered on the understanding of a shallow source of sound.

In April 1992, we recorded the acoustic pressure in excellent weather conditions (no fog, no rain, no wind) at a distance of $250 \mathrm{~m}$ for 36 explosions of the eastern vents of Stromboli. Acoustic pressure starts close to zero and increases (Figure 2). The radian frequency is low, less than $60 \mathrm{rad} \mathrm{s}^{-1}$ and the amplitude at a distance of 250 $\mathrm{m}$ is between a few and $50 \mathrm{~Pa}$. After one single cycle of vibration (i.e. the strong impulse event in acoustic pressure) the bubble bursts, emitting rather quiet higher frequencies. However, Vergniolle and Brandeis [1994] focused only on the frequency content and small oscillations of such a bubble. In this present paper, we broaden our scope and include amplitude of the acoustic pressure in order to bring constraints on such quantities as bubble diameter and length, thickness of magma layer, and overpressure.

\section{The Model}

\section{Assumptions}

A typical Strombolian bubble has a radius of $\approx 1$ $\mathrm{m}$ and its magma thickness $h$ at equilibrium, assumed to be close to the average diameter of ejecta, is $\approx 2$
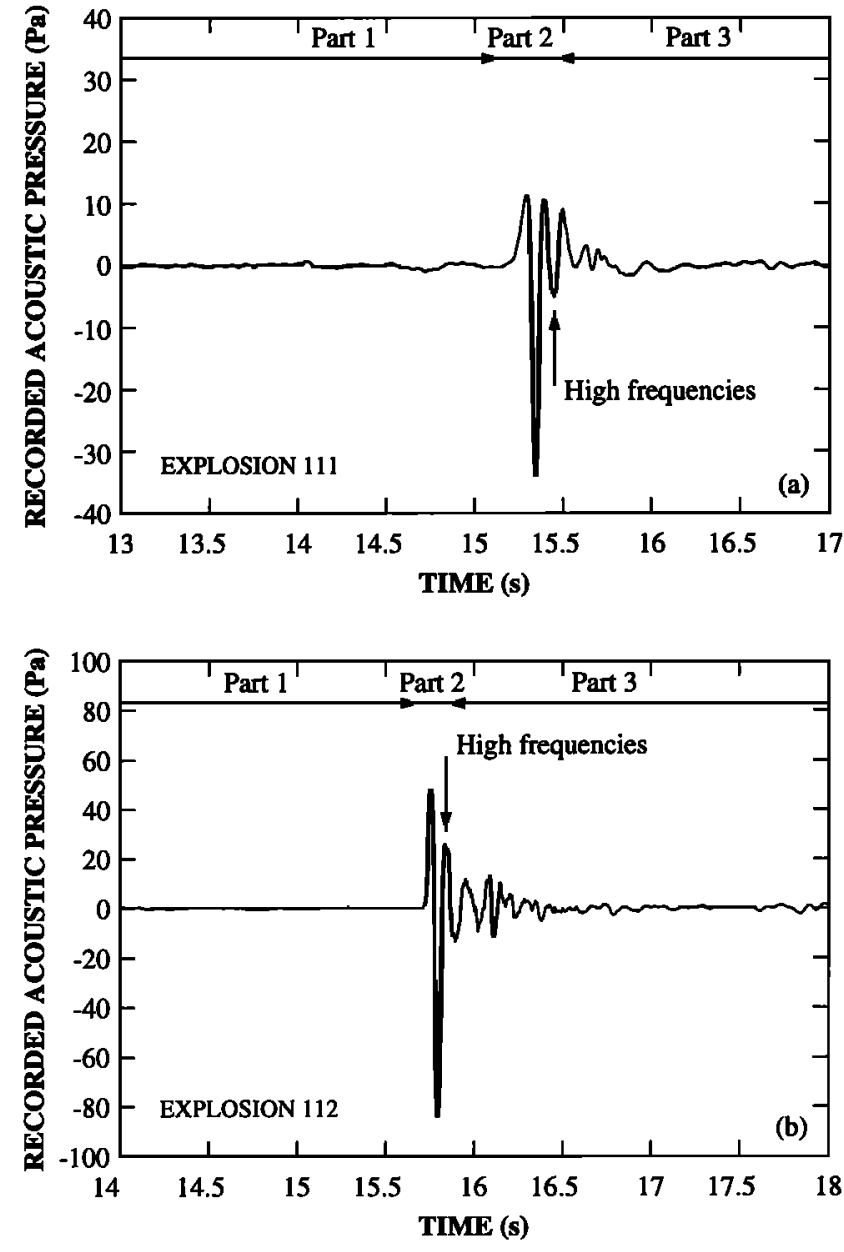

Figure 2. Acoustic pressure measured at $250 \mathrm{~m}$ from the source during explosions (a) 111 and (b) 112 of the eastern vent in 1992 .

$\mathrm{cm}$, small compared to the radius (Figure 1) [Vergniolle and Brandeis, 1994]. We approximate the bubble shape by a cylindrical tail and an hemispherical head, getting distorted at the air-magma interface (Figure 3a). Most of the observed vents consist of an opening surrounded by a small cone of ejecta, giving to the total structure the shape of a funnel. Therefore no external limitation exists on the bubble growth when the bubble reaches the surface. Because the magma is close to the surface for the eastern vents [Vergniolle and Brandeis, 1994], there is no amplification of the sound inside the upper part of the volcanic conduit (see Appendix A), and the distortion due to the propagation from the source to the microphone is small [Vergniolle and Brandeis, 1994]. We do not consider the exact vent geometry since it is not known accurately.

Finally, we have to specify the temperature inside the bubble. Before vibration, the bubble is in thermal equilibrium with the magma in the chamber. However, the following calculations are weakly sensitive to the specific temperature value. It will be chosen in the range of values obtained from experimental studies [Francalanci et al., 1989] and considered equal to $1373 \mathrm{~K}$. 


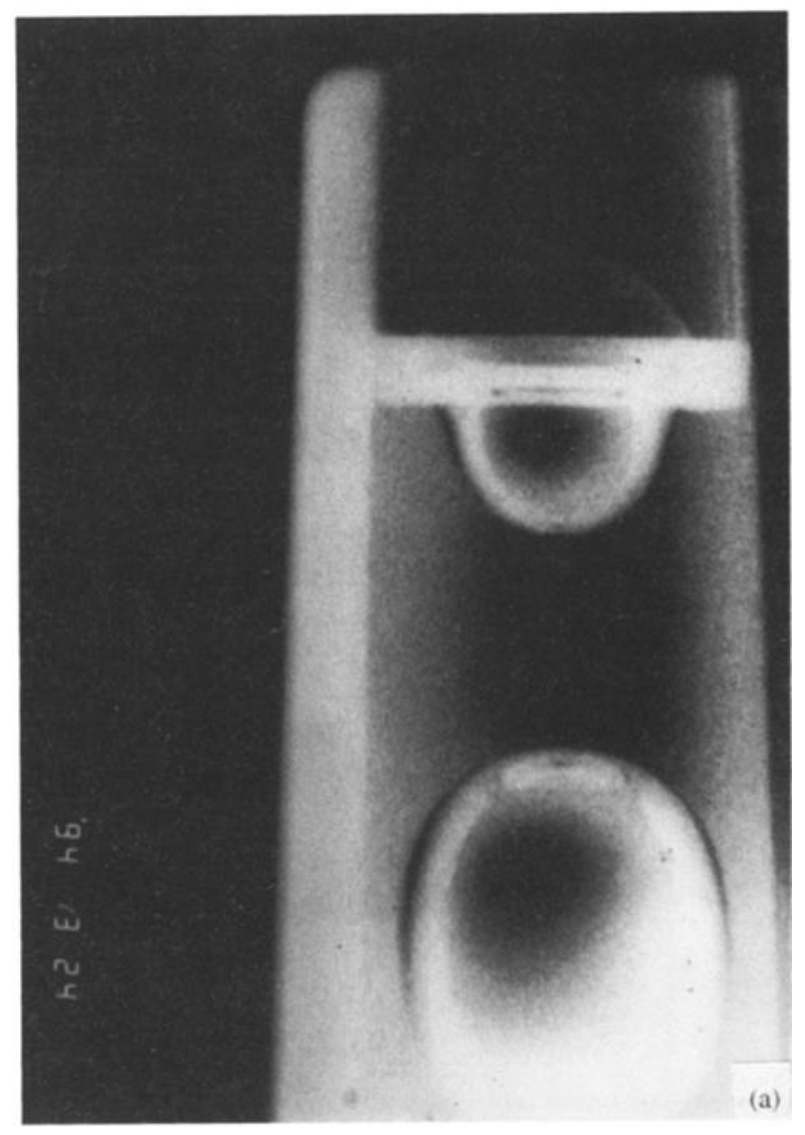

Figure 3a. Experiment showing the strong change in geometry experienced by a bubble reaching the liquidair interface. The liquid is a viscous silicon oil (12.5 Pa.s). Note the increase in diameter of the bubble cap and the small thickness of the liquid above the bubble.

In this study, we assume that the magma is a Newtonian liquid. This hypothesis can be violated either for dynamical reasons, or because of the cooling of magma. A viscous fluid can loose its Newtonian behavior if the time during which a force is applied to it is very small [Landau and Lifshitz, 1987]. For Strombolian magma, this relaxation time is around $4 \times 10^{-8} \mathrm{~s}$ [Webb and Dingwell, 1990], much less than the observed vibration time $(0.1 \mathrm{~s})$. Therefore the departure from the Newtonian rheology can be only due to the occurrence of crystals. Strombolian ejecta contains between 10 and $45 \%$ of phenocrysts [Francalanci et al., 1989]. However, there are no accurate data on the occurrence of crystal content in lava itself, and T. Trull (personal communication, 1995) suggests that this parameter is close to $25 \%$ for Strombolian lava. In these conditions, the magma rhelogy can be considered as Newtonian [Shaw, 1969; van der Molen and Paterson, 1979; Ryerson et al., 1988].

\section{Description of the Source}

We propose that the sound recorded at the vent of Stromboli is produced by the vibration of a metric bubble prior to bursting and close to the surface [Vergniolle

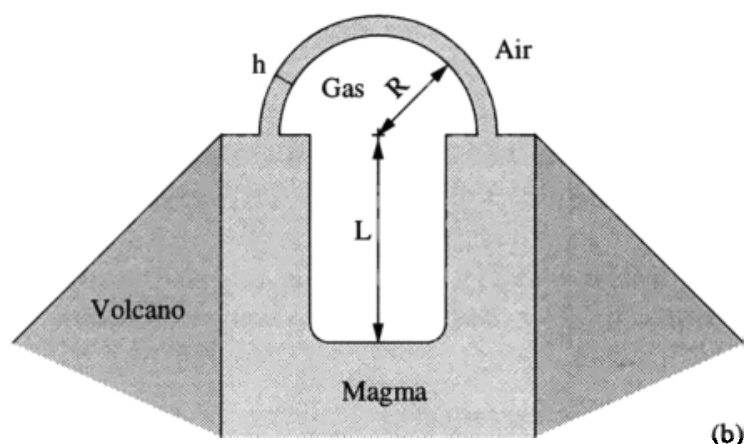

(b)

Figure 3b. Sketch of a vibrating bubble reaching the air-magma interface. The hemispherical cap above the bubble vibrates in air as a membrane of thickness $h$. The bubble has radius $R$ and length $L$.

and Brandeis, 1994]. Bubbles on the surface of lava flows at Etna have been observed bursting in May 1983 (Figure 1). Any bubble in an infinite liquid oscillates: inertia causes the bubble to overshoot its equilibrium radius and the compressibility of gas is the restoring force [Batchelor, 1967]. Here, we assume for simplicity that the oscillations are triggered by a sudden overpressure inside a large bubble reaching the magma-air interface. Four possible sources of overpressure can exist inside a bubble. The first one is surface tension at the gas-liquid interfaces. The second one is related to the significant delay imposed to the growth of a rising bubble due to the magma viscosity. The third one is related to the effect of the air-magma interface on the moving bubble, which induces a departure from steadiness in the upwards velocity. The fourth one is related to the energetic formation of the gas pocket by coalescence of a foam layer at the top of the magma chamber [Jaupart and Vergniolle, 1989]. All these sources of overpressure will be compared to our estimates of the bubble overpressure deduced from acoustic measurements.

A bubble vibrating at a magma-air interface presents three modes of vibration. The first mode is related to surface tension, the second one is related to gravity waves, and the third one is only due to volume changes and is called the volume mode [ $L u$ et al., 1989; Vergniolle and Brandeis, 1994]. The high frequency of the volume mode compared to surface tension or gravity modes [Vergniolle and Brandeis, 1994] indicates a strong restoring force, making it hard to excite $[L u$ et al., 1989]. Overpressure builds up inside a Strombolian bubble rising in a tube and induces its strong vibration at the magma-air interface. This leads to changes in the bubble volume: energy will go preferentially into the volume mode, directly driven by overpressure, rather than into the surface tension mode, which is not energetic for large bubbles, or into the gravity mode. Hence the present study will be focused only on the volume mode. A Strombolian bubble reaching the surface is halfway immersed into the magma and almost halfway in air despite a thin layer of magma above it (Figure 
$3 \mathrm{~b})$. Because of the large difference in viscosity between air and magma, the motion of the immersed part of the bubble is restricted [Vergniolle and Brandeis, 1994]. Therefore the bubble vibration is mostly concentrated into its hemispherical cap (Figure 3a). For simplicity, we ignore the elasticity of the magma shell.

The vibration of the interface between the bubble and the magma is transmitted radially through the thin layer of magma and reaches the magma-air interface. The sound speed in magma is above $2500 \mathrm{~m} \mathrm{~s}^{-1}$ [Rivers and Carmichael, 1987; Kress and Carmichael, 1991] for the shoshonite composition of Stromboli [Francalanci et al., 1989]. The magma is largely incompressible for the radial motion considered here. Therefore no energy is lost by transmission through the thin layer of magma [Pierce, 1981]: the magma-air interface vibrates as the bubble does.

\section{Radiation Pattern of the Source}

The source is a thin layer of magma, pushed by a variation of pressure inside the bubble. We have shown that the source is a monopole as its amplitude decreases inversely proportional to the distance between the microphone and the vent. Therefore the propagation of pressure waves is radial [Vergniolle and Brandeis, 1994], and in that case, the source is a simple one. The excess pressure can be described from the linear theory of sound. In that case, the basic variable is the rate of mass outflow from the source, $\dot{q}$, often called the strength of the source [Lighthill, 1978]. Acoustic pressure $p_{\text {ac }}$ emitted at the source at time $t$ will reach the microphone at a time $t+r / c$, where $r$ is the distance from the vent and $c$ is the sound speed in air $\left(340 \mathrm{~m} \mathrm{~s}^{-1}\right.$ at $900 \mathrm{~m}$ above sea level [Lighthill, 1978]). Here the magma-air interface is the radiating body which is half a sphere of radius equal to the bubble radius $R$. It emits sound in air in half a sphere of radius $r$, the distance between the vent and the microphone. For such a monopole source, the excess pressure $p_{\mathrm{ac}}-p_{\text {air }}$ at time $t$ is

$$
\begin{aligned}
p_{\mathrm{ac}}-p_{\mathrm{air}} & =\frac{\dot{q}(t-r / c)}{4 \pi r} \\
& =\frac{d^{2}}{d t^{2}}\left[\frac{4 \pi R^{3}(t-r / c)}{6}\right] \frac{\rho_{\mathrm{air}}}{2 \pi r}
\end{aligned}
$$

where $p_{\text {air }}$ and $\rho_{\text {air }}$ are respectively atmospheric pressure and air density $\left(1.1 \mathrm{~kg} \mathrm{~m}^{-3}\right.$ at $900 \mathrm{~m}$ above sea level [Batchelor, 1967]). Finally, we obtain the excess pressure in air

$$
\begin{aligned}
p_{\text {ac }}-p_{\text {alr }}= & {\left[2 \dot{R}^{2}(t-r / c)+R(t-r / c) \ddot{R}(t-r / c)\right] } \\
& \times \frac{\rho_{\text {air }} R(t-r / c)}{r}
\end{aligned}
$$

where $\dot{R}$ is the radial velocity and $\ddot{R}$ is the radial acceleration of the hemispherical cap. This equation relates the variations in acoustic pressure to the bubble vibration.

\section{Equations for the Bubble Vibration}

In order to express the variations in acoustic pressure, we model the bubble motions in response to a sudden overpressure. The bubble oscillates in the magma which is a newtonian viscous fluid. In Appendix B we show that the only significant source of damping on the bubble oscillations is due to viscous forces in the magma layer above the bubble.

The bubble vibrates as a thin membrane of thickness $h$. Its head grows but remains spherical with a radius $R$. The part of the bubble which remains in the cylindrical tube has a length $L$ (Figure 3a). Hence the bubble has a volume $V_{\mathrm{g}}$ equal to

$$
V_{\mathrm{g}}=\frac{2 \pi R^{3}}{3}+\pi R_{\circ}^{2} L
$$

where $R_{\circ}$ is the initial radius. Note that in the following, indexes $o, g$, and eq refer to initial conditions, gas, and equilibrium values, respectively. The high viscosity of magma impedes any significant drainage of magma above the bubble, during the short time allowed for the bubble to vibrate. The volume of magma above the bubble is conserved and the liquid streches, following the variations in bubble radius

$$
R^{2} h=R_{\text {eq }}^{2} h_{\text {eq }}
$$

Because heat transfer inside large bubbles is adiabatic [Plesset and Prosperetti, 1977], the pressure $p_{\mathrm{g}}$ inside the bubble follows the variations of its volume $V_{\mathrm{g}}$

$$
p_{\mathrm{g}} V_{\mathrm{g}}^{\gamma}=p_{\mathrm{g} \text { eq }} V_{\mathrm{g} \text { eq }}^{\gamma},
$$

where $\gamma$ is the ratio of specific heats, equal to 1.1 for hot gases [Lighthill, 1978 ]. For a thin layer of magma, the contribution of its weight to the equilibrium pressure inside the bubble is small, and the equilibrium pressure $p_{\mathrm{g} \text { eq }}$ can be considered as equal to the atmospheric pressure $p_{\text {air }}, 10^{5} \mathrm{~Pa}$. The temperature $T$ is homogeneous inside the gas during vibration [Prosperetti, 1986] and obeys the law of perfect gases

$$
T=T_{\circ} \frac{p_{\mathrm{g}} V_{\mathrm{g}}}{p_{\mathrm{g} \circ} V_{\mathrm{g} \circ}} .
$$

Therefore it will passively follow variations in volume and pressure. Suppose that the bubble, initially at rest at the magma-air interface, is suddenly overpressurized by an amount $\Delta P$. The bubble starts to grow and vibrate in response to that pressure change. Pressure and volume follow the adiabatic law; hence we can calculate their variations. The equilibrium radius $R_{\text {eq }}$ changes from $R_{\mathrm{o}}$ according to the adiabatic law

$$
R_{\mathrm{eq}}=\left\{\frac{3 R_{\mathrm{o}}^{2}}{2}\left[\left(\frac{2 R_{\mathrm{o}}}{3}+L\right)\left(1+\frac{\Delta P}{p_{\mathrm{air}}}\right)^{\frac{1}{\gamma}}-L\right]\right\}^{\frac{1}{3}}
$$

where $L$ is the bubble length. The bubble radius $R$ varies around its equilibrium radius $R_{\text {eq }}$ by 


$$
R=R_{\mathrm{eq}}(1+\varepsilon),
$$

where $\varepsilon$ is a dimensionless bubble radius. The bubble motion is possible through an exchange between the kinetic energy $E_{\mathrm{k}}$ of its hemispherical cap and the potential energy $E_{\mathrm{p}}$ inside the gas, which are

$$
\begin{aligned}
& E_{\mathrm{k}}=\pi \rho_{1} R_{\mathrm{eq}}^{2} h_{\mathrm{eq}} \dot{R}^{2} \\
& E_{\mathrm{p}}=-\int_{V_{\mathrm{o}}}^{V}\left(p_{\mathrm{g}}-p_{\text {air }}\right) d V .
\end{aligned}
$$

We can express the rate of change of kinetic energy $d E_{\mathrm{k}} / d t$ and potential energy $d E_{\mathrm{p}} / d t$ as a function of the variations in velocity $\dot{\varepsilon}$ and acceleration $\ddot{\varepsilon}$

$$
\begin{aligned}
\frac{d E_{\mathrm{k}}}{d t} & =2 \pi \rho_{\mathrm{l}} R_{\mathrm{eq}}^{4} h_{\mathrm{eq}} \dot{\varepsilon} \ddot{\varepsilon} \\
\frac{d E_{\mathrm{p}}}{d t} & =\left[p_{\text {air }}-p_{\mathrm{g} \text { eq }}\left(\frac{V_{\mathrm{g} \mathrm{eq}}}{V_{\mathrm{g}}}\right)^{\gamma}\right] \frac{d V_{\mathrm{g}}}{d t} .
\end{aligned}
$$

Their sum is equal to the rate of energy dissipation, which is assumed to be entirely due to viscous forces inside the film of magma (see Appendix B). The total rate of dissipation $\dot{F}_{\mathrm{v}}$ in a hemispherical film of thickness $h$ and viscosity $\mu$ can be calculated in the same way as for a sphere [Batchelor, 1967] and is equal to

$$
\dot{F}_{\mathrm{v}}=\int_{R}^{R+h} \frac{12 \pi R^{4}}{r^{6}} \dot{R}^{2} 2 \pi r^{2} d r=24 \pi \mu \dot{R}^{2} h_{\mathrm{eq}}
$$

We obtain the general equation for the bubble vibration

$$
\ddot{\varepsilon}+\left(\frac{12 \mu}{\rho_{\mathrm{l}} R_{\mathrm{eq}}^{2}}\right) \dot{\varepsilon}+\frac{p_{\text {air }}\left[1-\left(\frac{V_{\mathrm{eq}}}{V_{\mathrm{s}}}\right)^{\gamma}\right]}{\rho_{1} R_{\mathrm{eq}} h_{\mathrm{eq}}}(1+\varepsilon)^{2}=0
$$

where $V_{\mathrm{g}}$ is a function of $\varepsilon$ (equation (8)) and $\beta_{\mathrm{v}}$ is the viscous damping coefficient

$$
\beta_{\mathrm{v}}=\frac{6 \mu}{\rho_{1} R_{\mathrm{eq}}^{2}} .
$$

The first initial condition to be specified is the initial value of the dimensionless radius $\varepsilon_{o}$. The second initial condition is the initial radial acceleration $\ddot{\varepsilon}_{0}$, which depends on the initial force applied to the layer of magma. Assuming that the bubble, at rest at the magma-air interface, is suddenly overpressurized by an amount $\Delta P$, this force is directly related to the bubble overpressure. Therefore the initial conditions are

$$
\begin{aligned}
\ddot{\varepsilon}_{\mathrm{o}} & =\frac{\Delta P R_{\mathrm{o}}^{2}}{\rho_{1} R_{\mathrm{eq}}^{3} h_{\mathrm{eq}}} \\
\varepsilon_{\mathrm{o}} & =\frac{R_{\mathrm{o}}}{R_{\mathrm{eq}}}-1 .
\end{aligned}
$$

Radial acceleration is maximum when the strong vibration starts, and therefore the initial radial velocity is equal to zero. These initial conditions correspond to a bubble close to its minimum radius.

\section{Small Oscillations Without Damping}

Equation (12) has an analytical solution when the variation in bubble radius $\varepsilon$ is small $(\ll 1)$. Without damping, the solution of $\varepsilon$ is a sine function, whose amplitude $A$, radian frequency $\omega$, and phase delay $\phi$ are

$$
\begin{aligned}
A & =\frac{\Delta P R_{\mathrm{o}}^{2}}{3 \gamma p_{\mathrm{air}} R_{\mathrm{eq}}^{2}}\left(\frac{2+3 L / R_{\mathrm{eq}}}{2}\right) \\
\omega & =\left[\frac{3 \gamma p_{\mathrm{ext}}}{\rho_{\mathrm{l}} R_{\mathrm{eq}} h_{\mathrm{eq}}}\left(\frac{2}{2+3 L / R_{\mathrm{eq}}}\right)\right]^{1 / 2} \\
\phi & =-\frac{\pi}{2}
\end{aligned}
$$

where $p_{\text {ext }}$ is close to the atmospheric pressure $p_{\text {air }}$, $10^{5} \mathrm{~Pa}$, for a bubble close to the air-magma interface. The phase delay, $\phi$, in the sine function corresponds to a bubble initially at its minimum radius. The results show that the amplitude of the vibration is directly related to the overpressure in the bubble. Similarly, the frequency of the vibration depends on the size of the source, here both on the bubble volume and on the thickness of the magma layer: the larger the source, the lower the frequency of vibration is.

Such a source will produce an excess of acoustic pressure $p_{\mathrm{ac}}-p_{\mathrm{alr}}$ at a distance $r$ and at a time $t+r / c$

$$
p_{\text {ac }}-p_{\text {arr }}=-\rho_{\text {air }} R_{\text {eq }}^{3} \frac{A \omega^{2}}{r} \sin (\omega t+\phi) .
$$

The radial velocity is maximum for equilibrium, where acceleration is zero, and zero close to the minimum or maximum radius, where acceleration is maximum. Acoustic pressure, which depends mainly on acceleration, starts at its highest positive value before decreasing toward zero (Figure 4a). It is clear from the comparison between model and data (Figure 2) that either hypotheses on small oscillations or no damping or both are not appropriate. Therefore we need to take into account the nonlinearity of equation (12) and the viscous damping.

\section{The General Case}

In this section, we solve the general case for the bubble vibration (equation (12)). Equation (12) is an ordinary differential equation of order 2 . Its behavior can be understood by looking at the stability of equilibrium points and their local behavior when assuming small oscillations [Drazin, 1992]. The equilibrium points are found by setting at zero the acceleration in equation (12). Ignoring viscous damping (since we show it is small) and assuming small oscillations, our equation has only one physically possible solution, which is a simple oscillator. Its phase diagram will be discussed later.

If the vibration of a bubble is not small, equation (12) has no analytical solution. We solved it by numerical integration (a second- and third-order Runge and Kutta method). In order to find the behavior of the solution, 

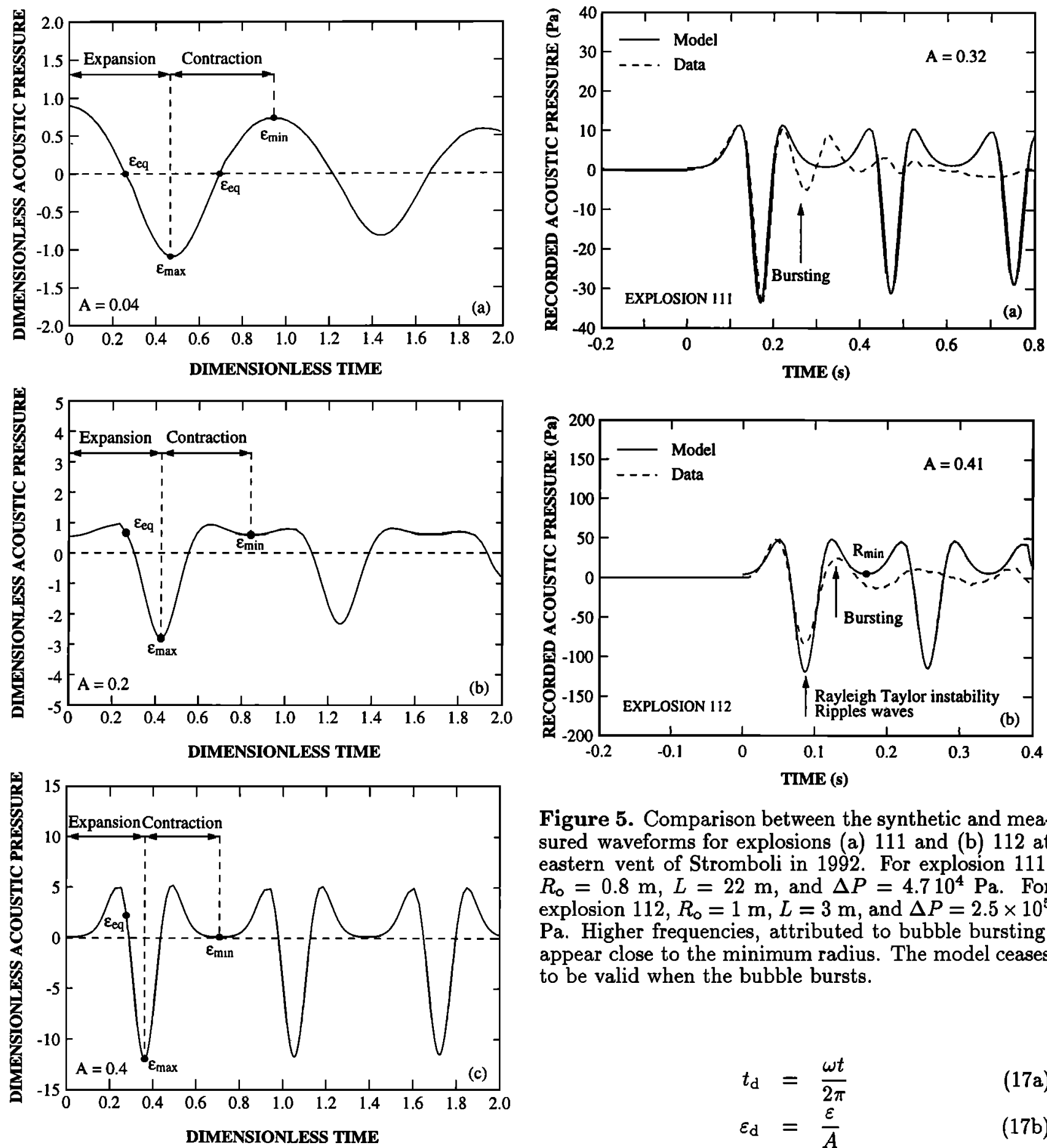

Figure 4. Acoustic pressure in time with dimensionless units. Initial radius $R_{\circ}$ is $1 \mathrm{~m}$, length $L$ is $10 \mathrm{~m}$, and equilibrium thickness of magma above the bubble $h_{\text {eq }}$ is $2 \mathrm{~cm}$. Maximum $\varepsilon_{\max }$, minimum $\varepsilon_{\min }$ and equilibrium dimensionless radii $\varepsilon_{\text {eq }}$ are shown. (a) $\Delta P=10^{3} \mathrm{~Pa}$ and $A=0.04$. (b) $\Delta P=10^{4} \mathrm{~Pa}$ and $A=0.2$. (c) $\Delta P=5 \times 10^{5} \mathrm{~Pa}$ and $A=0.4$.

we express the variables in a dimensionless form with respect to their values for the small oscillation case. The amplitude of the oscillations $A$ can be used as a length scale and the radian frequency $\omega$ as a timescale. The dimensionless variables are

$$
\begin{aligned}
t_{\mathrm{d}} & =\frac{\omega t}{2 \pi} \\
\varepsilon_{\mathrm{d}} & =\frac{\varepsilon}{A} \\
\dot{\varepsilon}_{\mathrm{d}} & =\frac{\dot{\varepsilon}}{A \omega} \\
\ddot{\varepsilon}_{\mathrm{d}} & =\frac{\ddot{\varepsilon}}{A \omega^{2}} \\
\left(p_{\mathrm{ac}}-p_{\mathrm{air}}\right)_{\mathrm{d}} & =\frac{\left(p_{\mathrm{ac}}-p_{\mathrm{air}}\right) r}{\rho_{\mathrm{air}} R_{\mathrm{eq}}^{3} A \omega^{2}} .
\end{aligned}
$$

Figure 4 shows the strong influence of amplitude $A$. As $A$ increases, the difference between positive and negative peaks in acoustic pressure gets stronger, and initial acoustic pressure tends to zero. Comparison with data (Figure 2) shows clearly that $A$ needs to be at least 

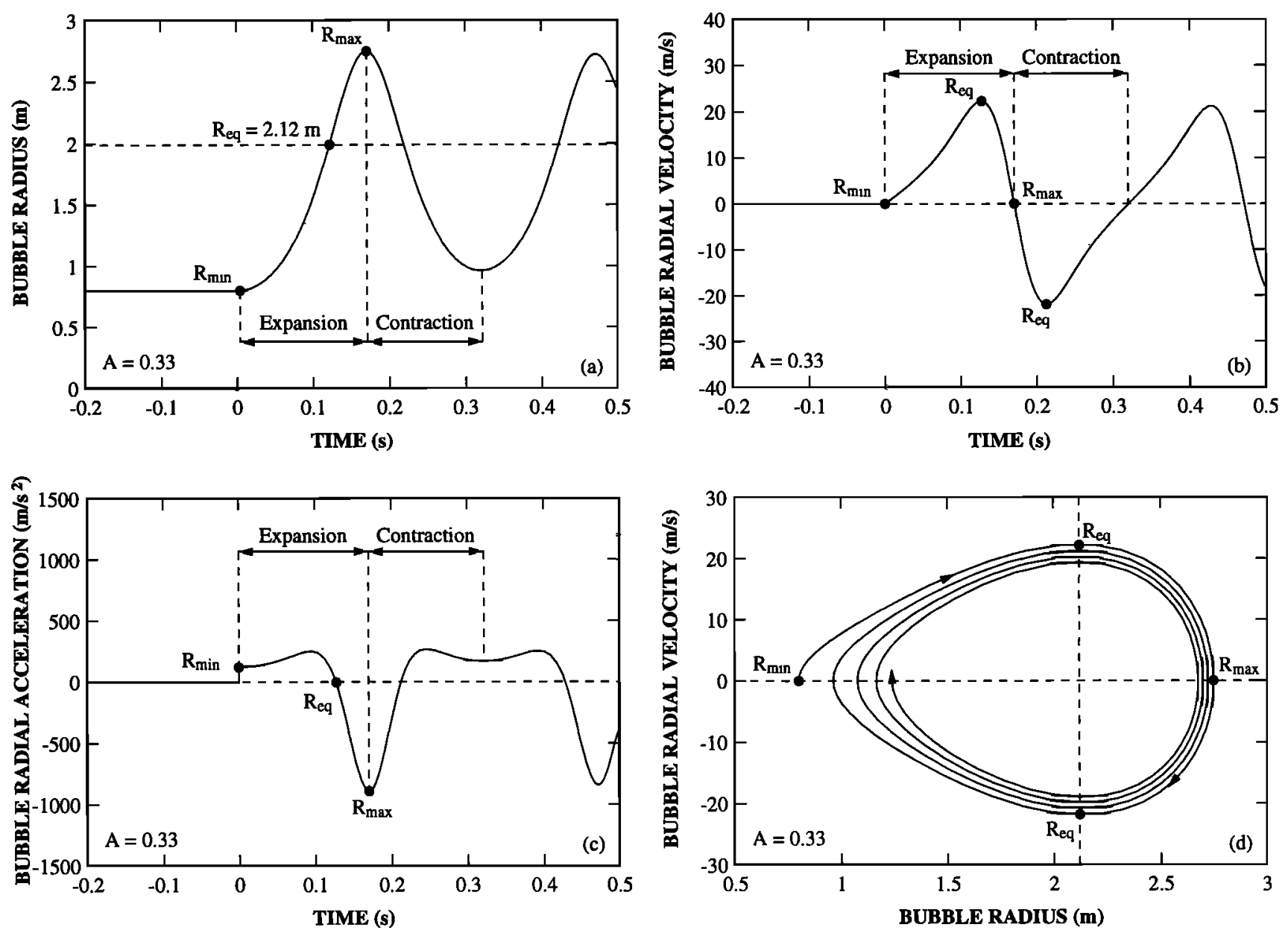

Figure 6. Variations with time of (a) bubble radius, (b) velocity, and (c) acceleration for a bubble with $R_{\circ}=0.8 \mathrm{~m}, L=22 \mathrm{~m}$, and $\Delta P=4.7 \times 10^{4} \mathrm{~Pa}$. Equilibrium thickness of magma above the bubble, $h_{\mathrm{eq}}$, is $2 \mathrm{~cm}$ and amplitude of small oscillations $A$ is equal to 0.33 . Corresponding positions of minimum $R_{\min }$, equilibrium $R_{\text {eq }}$, and maximum $R_{\max }$ radii are shown. (d) Phase trajectory showing that damping is small.

equal to 0.3 in order to reproduce correctly the observed acoustic pressure (Figure 4).

\section{Applications to Strombolian Explosions}

In this section, we compare the acoustic pressure predicted by the model to the measurements. Acoustic pressure produced by the bubble vibration is entirely determined by the initial conditions, such as the bubble geometry and its pressure, and by the characteristics of the magma, such as the viscosity and density, assumed here to be $400 \mathrm{~Pa} \mathrm{~s}$, from physical and chemical modeling [Shaw, 1972] and magma composition at Stromboli [Capaldi et al., 1978], and $2700 \mathrm{~kg} \mathrm{~m}^{-3}$, respectively. The four parameters (radius, length, overpressure, thickness of magma layer) cannot be determined independently and simultaneously unless the regime is highly nonlinear, $A>0.5$. We have allowed one parameter, the magma layer thickness $h$, to vary in a reasonable range, from 0.5 to $10 \mathrm{~cm}$, according to observed sizes of ejecta [Chouet et al., 1974]. Then we fit the calculated waveform to the recorded one. This allows determination of the three other parameters, bubble radius, length and overpressure.

\section{Qualitative Results}

The fit between predicted and measured acoustic pressure is good for about one cycle, until high frequencies appear after the first cycle of vibration (Figures 2 and 5), probably generated by the bursting of the bubble after which our model obviously ceases to be valid. Three different features of the acoustic pressure are very well reproduced: the shape of acoustic pressure during rising time, the relative intensities, and the durations of positive and negative peaks.

The behavior of radius, velocity, acceleration, and, consequently, acoustic pressure is summarized on Figures 6 and 7 . As a consequence of the variation in its radius (Figure 6a), the bubble takes a distorted shape with a head twice as large as its bottom, as observed in 

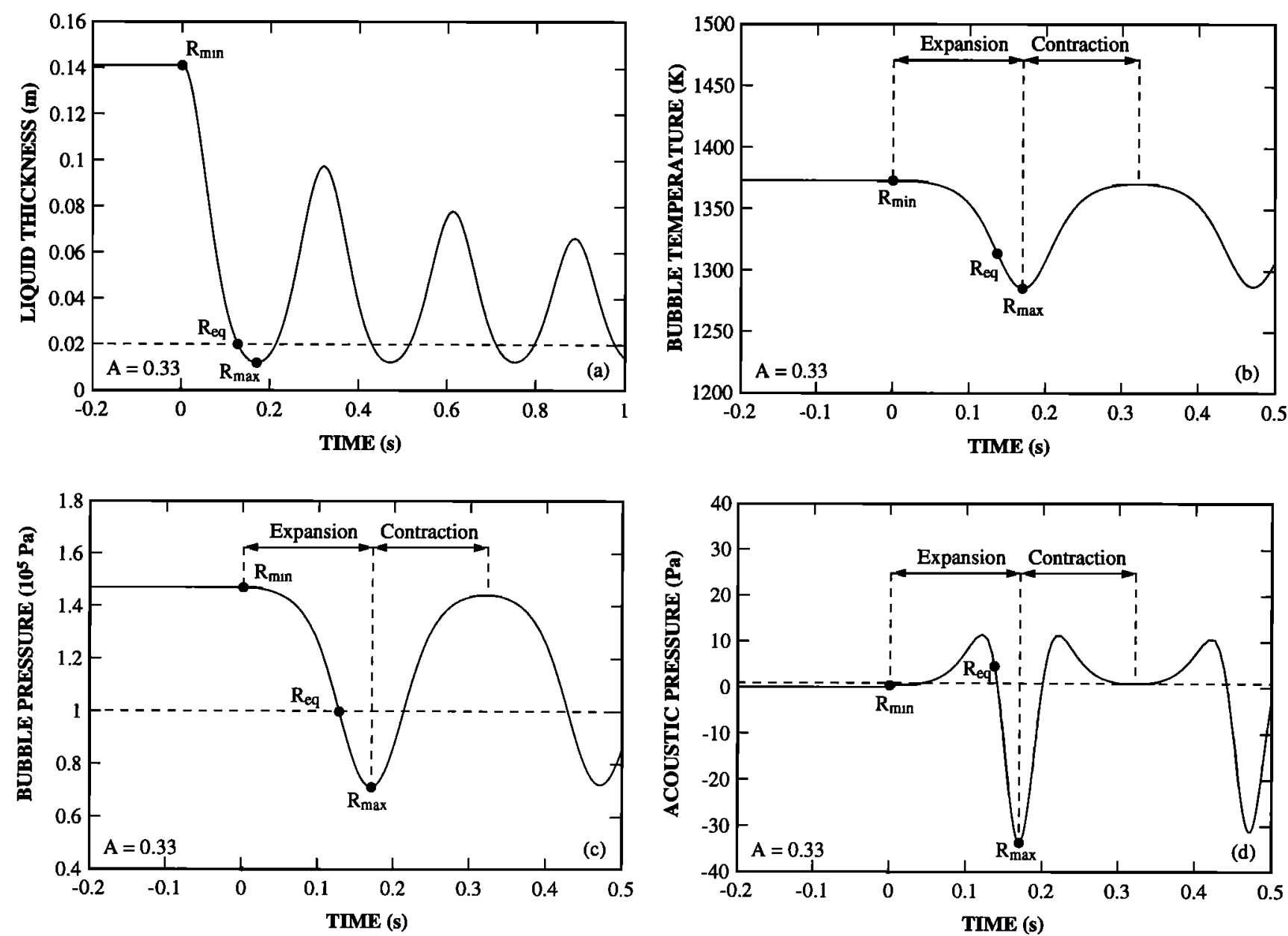

Figure 7. Variations of (a) liquid thickness, (b) temperature, (c) bubble internal pressure, and (d) acoustic pressure with time for same set of parameters and initial conditions as in Figure 6.

laboratory experiments (Figure $3 \mathrm{a}$ ). The phase trajectory, fairly different from a circle (Figure 6d), exhibits a spiral node [Drazin, 1992], confirming that the bubble is a simple nonlinear oscillator with a small damping coefficient. The damping is stronger close to the minimum radius, where the film of magma is the thickest than close to the maximum radius (Figure 6d). The magma thickness $h$ (Figure 7a) is small compared to the bubble radius $R$ (Figure 6a), in agreement with the assumptions. The variation in the gas temperature, although here almost $100 \mathrm{~K}$ (Figure $7 \mathrm{~b}$ ), does not allow a significant cooling of the magma during the short time of vibration, less than $0.1 \mathrm{~s}$.

\section{Source Characteristics}

Numerical values of bubble radius, bubble length, overpressure and amplitude $A$ are displayed for different values of the magma layer thickness in Table 1. The skin thickness $h$ is the most critical parameter of our calculations. It is clear that thicknesses above $5 \mathrm{~cm}$ lead to unlikely values of overpressure, above $10^{7} \mathrm{~Pa}$, and high amplitudes $A$, above 1 , for which results become very sensitive to the choice of initial conditions. For values of $h$ between 0.5 and $2 \mathrm{~cm}$, the radius $R_{\mathrm{o}}$ varies only by $15 \%$, while the bubble length $L$ varies by a factor of 4.5 , from about $7 \mathrm{~m}$ to about $30 \mathrm{~m}$. The overpressure

Table 1. Influence of Equilibrium Thickness on Bubble Characteristics Error bars correspond to one standard deviation.

\begin{tabular}{rcrrc}
\hline$h_{\text {eq }}(\mathrm{cm})$ & $R_{\mathrm{o}}(\mathrm{m})$ & \multicolumn{1}{c}{$L(\mathrm{~m})$} & $\Delta P\left(10^{5} \mathrm{~Pa}\right)$ & $A$ \\
\hline 0.5 & $1.05 \pm 0.15$ & $33 \pm 12.5$ & $0.32 \pm 0.2$ & $0.31 \pm 0.02$ \\
1.0 & $1.05 \pm 0.15$ & $15.6 \pm 6.0$ & $0.69 \pm 0.3$ & $0.32 \pm \mathbf{0 . 0 2}$ \\
2.0 & $0.90 \pm 0.30$ & $7.3 \pm 3.0$ & $2.0 \pm 1.8$ & $0.37 \pm 0.03$ \\
5.0 & $0.80 \pm 0.30$ & $1.9 \pm 1.0$ & $8.4 \pm 4.0$ & $0.59 \pm 0.14$ \\
10.0 & $0.45 \pm 0.10$ & $0.7 \pm 0.9$ & $107 \pm 70.0$ & $1.13 \pm 0.25$ \\
\hline
\end{tabular}


varies by a factor of 6 , between $0.32 \times 10^{5}$ and $2 \times 10^{5}$ $\mathrm{Pa}$. The appropriate thicknesses of the magma layer are in good agreement with those of Chouet et al. [1974], who observed that $90 \%$ of ejecta had sizes between 0.6 and $4.5 \mathrm{~cm}$. Despite some variation (Table 1), the results are rather robust, with a bubble radius around 1 $\mathrm{m}$, a bubble length between a few and tens of meters, and an overpressure around $10^{5} \mathrm{~Pa}$. Their robustness is confirmed by the low values of $A$, between 0.3 and 0.4 (Table 1), which ensures an only mild nonlinearity and a weak sensitivity of results to initial conditions. Hence, for the sake of simplicity, in the following we fix the equilibrium thickness $h_{\text {eq }}$ at $2 \mathrm{~cm}$, keeping in mind that slight variations should be expected.

Despite variations, the values of initial bubble length are between 2 and 30 times those of the initial radius (Figure 8a), characteristic of a well-developed slug flow [Wallis, 1969]. The bubble radius itself has values $0.9 \pm 0.3 \mathrm{~m}$ (Figure $8 \mathrm{a}$ ) in good agreement with observations made at Stromboli [Chouet et al., 1974; Black- burn et al., 1976]. The scatter in bubble radius values might reflect the existence of several vents with different sizes. The maximum radial velocity in the hemispherical cap ranges between 8 and $60 \mathrm{~m} \mathrm{~s}^{-1}$ (Figure 8b), values compatible with independent measurements of velocities of around $40 \mathrm{~m} \mathrm{~s}^{-1}$ for ejecta and of $80 \mathrm{~m} \mathrm{~s}^{-1}$ for gas [Chouet et al., 1974; Weill et al., 1992]. The initial overpressure $\Delta P$ varies between $2 \times 10^{4} \mathrm{~Pa}$ and $6 \times 10^{5} \mathrm{~Pa}$ (Figure 8b), much larger than the previous estimate of $600 \mathrm{~Pa}$, derived from ballistic measurements at Stromboli, but comparable to that calculated at Heimaey, $2.5 \times 10^{4} \mathrm{~Pa}$, although this later volcano is considered to be more explosive [Chouet et al., 1974; Blackburn et al., 1976]. A striking feature apparent on Figure $8 \mathrm{~b}$ is the good correlation between maximum velocity and initial overpressure. This is the consequence of the mild departure from linear, small oscillations. The corresponding radial accelerations are of $550 \pm 300$ $\mathrm{m} \mathrm{s}^{-2}$ for the positive (outward) ones and of $1300 \pm 600$ $\mathrm{m} \mathrm{s}^{-2}$ for the negative (inward) ones, somewhat higher
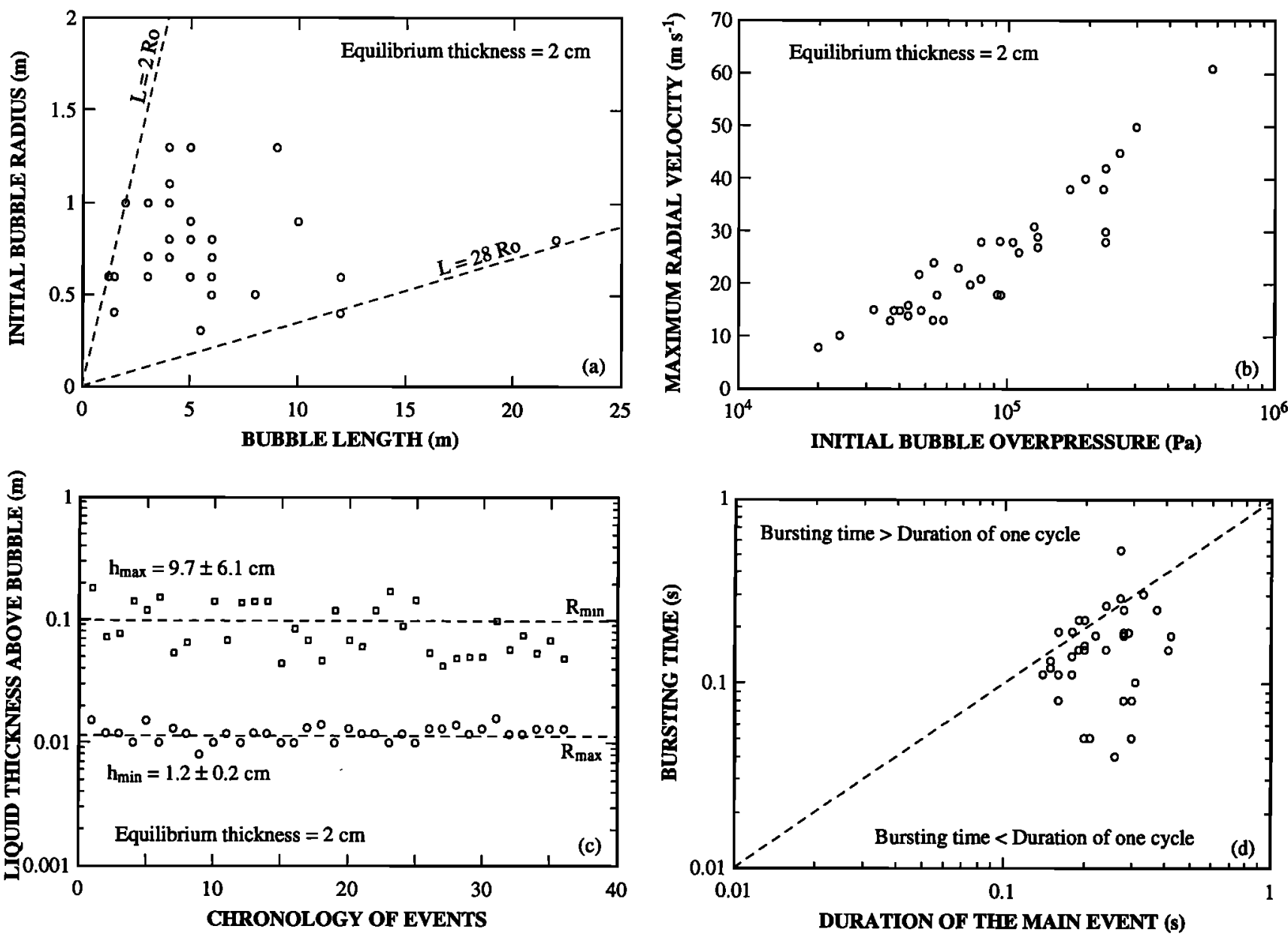

Figure 8. Results of the analysis of the 36 explosions recorded in April 1992 from the eastern vents. (a) Initial radius $R_{\circ}$ versus bubble length $L$ showing that length is larger than radius, trademark of a well-developed slug flow. (b) Radial velocity versus initial overpressure inside the bubble. (c) Liquid thicknesses at minimum and maximum radii. Ripple waves will preferentially develop when radius is maximum. (d) Bursting time versus duration of one cycle. For most explosions, bursting occurs before one cycle is completed. 
than previous estimates at Heimaey, from 250 to 600 $\mathrm{m} \mathrm{s}^{-2}$ [Blackburn et al., 1976], in agreement with the higher initial overpressure at Stromboli.

From the geometry of the bubble and the thickness of the magma above the bubble, we have calculated the volume of gas and ejecta emitted during one explosion. The volume of gas, at atmospheric pressure, varies between 2 and $100 \mathrm{~m}^{3}$ (Figure 9), in good agreement with airborne measurements, between 44 and $178 \mathrm{~m}^{3}$ ejected per second of explosion [Allard et al., 1994]. The volume of liquid above the bubble varies between 0.07 and $1 \mathrm{~m}^{3}$ (Figure 9), compatible with previous estimates for the eastern vents, obtained independently, from $9 \times 10^{-3} \mathrm{~m}^{3}$ [Blackburn et al., 1976] to $1.9 \mathrm{~m}^{3}$ [Ripepe et al., 1993]. This suggests that ejecta come mostly from the magma layer above the bubble and not from the walls of the conduit below.

\section{Sensitivity of Results to Input Parameters}

We have so far kept the liquid density $\rho_{\text {liq }}$ and viscosity $\mu$ constant, $2700 \mathrm{~kg} \mathrm{~m}^{-3}$ and $400 \mathrm{~Pa} \mathrm{~s}$, respectively. If the magma layer above the large bubble contains tiny bubbles, its density can decrease to about $2000 \mathrm{~kg} \mathrm{~m}^{-3}$ for a $30 \%$ vesicularity. We have verified that this decrease in density has only minor consequences on our results: the initial bubble radius $R_{\mathrm{o}}$ does not change and the bubble length $L$ increases by only $30 \%$, while the initial overpressure decreases by also $30 \%$. If the viscosity is below $1000 \mathrm{~Pa} \mathrm{~s}, 10$ times the value generally adopted at Stromboli [Blackburn et al., 1976], results are independent of its exact value, simply because the damping is small. Higher values of viscosity can be discarded (see discussion by Vergniolle et al., [this issue]).

\section{Discussion}

\section{Differences Between Measurements and Model}

Although most waveforms can be reasonably well reproduced (Figure 5a), it is sometimes difficult to fit the details of the first negative peak of acoustic pressure (Figure 5b) and consecutives oscillations. These discrepancies between observed and synthetic waveforms are probably related to our simplifying assumptions.

The main assumption of the model is that the bubble cap is perfectly hemispherical, whatever the velocities and accelerations are. Experiments [Taylor and Davies, 1963] have shown that bubbles tend to become spherical during expansion while, in contrast, they tend to loose their symmetry during contraction. Consequently, departure from sphericity would therefore be expected close to the minimum radius, when the acoustic pressure is zero. This could explain the mild discrepancies between observed and synthetic acoustic pressure during the first contraction (Figure 5b). We have also assumed that the rising motion of the bubble stops at

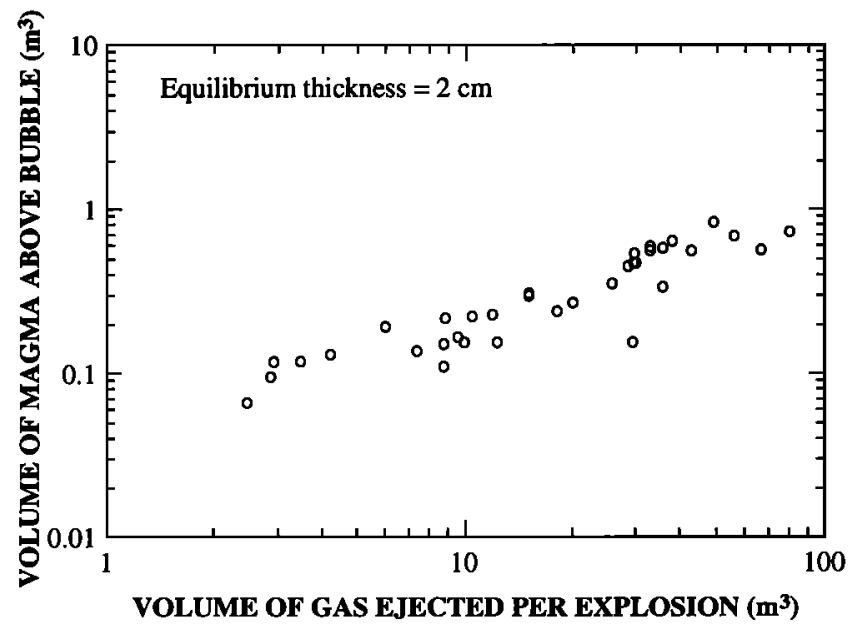

Figure 9. Volumes of gas and magma ejected during the 36 explosions.

the air-magma interface. However, if the magma above the bubble is still draining, the bottom of the bubble is still rising, thus increasing the pressure in the bubble. This could explain why the calculated acoustic pressure is larger than the measured one close to the maximum radius (Figures $5 \mathrm{~b}$ and $7 \mathrm{~d}$ ).

As on any air-liquid interface, surface waves can develop at the gas-magma and air-magma interfaces. Because the magma layer is thin, less than a few tens of centimeters (Figure 8c), ripple waves, controlled by surface tension [Lighthill, 1978], are more likely than pure gravity waves. They develop either in an antisymmetric, nondispersive way (snake mode) or in a dispersive symmetrical way (varicose mode) [Taylor, 1959]. Because the film is thinner, $\leq 2 \mathrm{~cm}$ (Figure $8 \mathrm{c}$ ), when the bubble radius is maximum, these ripple waves will be stronger and therefore will more affect the magma layer close to the maximum radius. The growth of these waves would take energy from the radial volume mode, which could account for the exageration in the calculated negative acoustic pressure.

Instabilities developing at the gas-magma and airmagma interfaces might also modify the spherical geometry of the bubble cap. A Rayleigh-Taylor instability develops along a planar interface when two fluids of different densities are accelerated toward each other [Chandrasekhar, 1961]. However, the stability of a spherical surface depends not just on its acceleration but on its velocity. During bubble growth, from $R_{\min }$ to $R_{\max }$, the streamlines diverge and produce a stabilizing effect on the inner interface [Prosperetti, 1986; Leighton, 1994]. Viscosity also slows down the growth on instabilities, but calculations become exceedingly difficult. However, close to the maximum radius, the film of magma is less than $2 \mathrm{~cm}$ and surface tension tends to stabilize the growth of these instabilities. Thus departure from perfect sphericity would be moderate, inducing a equally moderate discrepancy between observed 
and calculated acoustic pressure. The interaction of all these factor is very complex, which prevents a real quantitative assessment of their effects on the shape of the bubble and therefore on the acoustic pressure.

\section{Bursting}

It is clear that our model fails to reproduce the observed acoustic pressure just before the bubble radius has returned to its minimum value at the end of the first cycle, where higher frequencies appear (Figures 5 and 8d). This is a strong indication that the bubble cap stops to oscillate and bursts at this moment.

Contrasting with what happens near the maximum radius, both outward acceleration and inward velocity contribute to enhance the development of the RayleighTaylor instabilities at the inner interface [Prosperetti, 1986; Leighton, 1994], when the bubble radius is between $R_{\text {eq }}$ and $R_{\min }$. The destabilization of the spherical shape is maximum near the point where the inward motion is rapidly stopped and reversed [Plesset and Mitchell, 1956; Prosperetti, 1986]. Although this theory has been developed for small bubbles, experiments have shown that it applies also to large bubbles with strong accelerations, like those produced by underwater explosions [Taylor and Davies, 1963]. Since Strombolian bubbles undergo also large accelerations (Figure 6c), we believe that the same mechanism is at work at Stromboli.

The exponential growth of the Rayleigh-Taylor instability will ultimately lead to the rupture of the magma layer into fragments. Although the magma layer had a small inward radial velocity, these dispersed fragments are now subject only to the strong pressure difference between the volcanic gas and the atmosphere. They will therefore be propelled outward (Figure 1b). This could be further amplified by the presence of an extra pressure due to the still rising bottom of the bubble (see above).

\section{Origin of Overpressure}

This study suggests that Strombolian bubbles are overpressurized when they break at the surface of the lava column. We have suggested above four possible sources for this overpressure.

First, surface tension is known to allow excess pressure within bubbles. Surface tension between gas and magma is about $0.4 \mathrm{~N} \mathrm{~m}^{-1}$ [Walker and Mullins, 1981] showing that this effect is small for metric bubbles and can be ruled out.

When a bubble rises in a viscous liquid, the viscosity prevents the pressure in the bubble to adjust instantaneously to the decreasing external pressure. For a spherical bubble growing in an infinite liquid, the overpressure $\Delta P_{v}$ between a bubble of radius $R$ and the liquid directly above it is equal to

$$
\Delta P_{v}=\frac{4 \mu \dot{R}}{R}
$$

where $\mu$ is the liquid viscosity and $\dot{R}$ is the radial velocity of the bubble-magma interface for steady growth [Sparks, 1978; Leighton, 1994]. Since bubble growth is due to its upward motion, $\dot{R}$ scales as the rise speed, $\approx$ $1.5 \mathrm{~m} \mathrm{~s}^{-1}$. For a magma of $400 \mathrm{~Pa} \mathrm{~s}$, the viscous overpressure reaches at most a value around $3 \times 10^{3} \mathrm{~Pa}$, far below our estimates $\left(\approx 10^{5} \mathrm{~Pa}\right)$. Therefore this mechanism is probably not efficient at depth where the rising velocity is steady.

When the bubble gets closer to the top of the magma column, its upward motion becomes unsteady, with large accelerations away from the interface when the bubble is expanded and small accelerations toward the interface when the bubble is contracted [Leighton, 1994]. This will create a significant overpressure, difficult to quantify, inside the bubble, as pressure and acceleration are directly related.

From experimental work, it has been suggested that the bubbles at Stromboli result from the coalescence at depth of a foam layer of small bubbles, from $1 \mathrm{~mm}$ to $1 \mathrm{~cm}$ [Jaupart and Vergniolle, 1988, 1989]. This process suddenly releases an excess pressure related to the surface tension of each bubble [Jaupart and Vergniolle, 1989]. At the estimated depth of the magma chamber, a few hundred of meters [Giberti et al., 1992], the excess pressure in the new gas pocket is of the order of the lithostatic pressure, $\approx 10^{7} \mathrm{~Pa}$. This coalescence can trigger the oscillations in volume of the new gas pocket. The superposition of these oscillations with the bubble rise is complex; therefore it is difficult to quantify the overpressure at the surface from its value at depth. Although, at this stage, we cannot discriminate between a deep and a shallow origin of overpressure in the bubble when it reaches the surface, our model is able to reproduce the recorded acoustic pressure with good accuracy.

\section{Alternate Models}

Although our model is satisfactory in reproducing acoustic pressure, other mechanisms can be envisaged.

Azbel [1981] has proposed that when the liquid layer reaches a critical thickness, it vibrates in resonance with the volume mode of the bubble beneath, which triggers its rupture. For Strombolian bubbles, the radian frequency of a membrane of $2 \mathrm{~cm}$ in thickness is around $0.3 \mathrm{rad} \mathrm{s}^{-1}$, much below our acoustic measurements. Because resonance is known to concentrate energy in a very narrow frequency range, this mechanism does not explain why a significant amount of energy is released at the measured radian frequency, $\approx 60 \mathrm{rad} \mathrm{s} \mathrm{s}^{-1}$. The observation that sound is produced when small bubbles burst at the surface of the ocean has led Spiel [1992] to suggest that these bubbles behave like a Helmoltz resonator, i.e., a rigid cavity with a small hole through which the gas escapes and produces sound. Applied to metric bubbles, such at Stromboli, this mechanism predicts a internal overpressure of $1 \mathrm{~Pa}$. Since the acoustic 
pressure is still above several pascals at $250 \mathrm{~m}$ from the source (Figure 2), we feel that this mechanism should be discarded.

Other mechanisms, which call for a deep source, for example such as a air gun [Avedik et al., 1993], can be envisaged. Recently, Buckingham and Garcés [1996] have proposed that the sound originates from a deep and explosive source. The calculated power spectrum matches the observed one with a reasonable accuracy. However, this model predicts a conduit diameter 6 times larger than the one observed at the surface and a pressure excess 30 times the lithostatic pressure. Such a large overpressure could be easily obtained by highly reacting gas species, but the chemistry and the amount of gases present at Stromboli are far below the critical amount for explosivity (F. Le Guern, personal communication, 1995). Although the mechanism responsible for such a deep energetic source has still to be discovered, this model may provide an alternative to our model.

\section{Conclusion}

Our model, based on physical phenomena that have been observed in many laboratory experiments, provides a simple explanation for the sound produced during Strombolian explosions. When a large bubble, coming from depth, reaches the top of the magma column, internal overpressure forces its cap to inflate until it reaches a maximum value. Then it deflates back toward its initial value. Just before the minimum radius is reached, the bubble breaks, probably by instability developing on the thin magma layer.

From the fit between observed and synthetic waveforms of acoustic pressure, we predict that the bubble radius is of the order of $1 \mathrm{~m}$, in agrement with observed vent sizes. The length of the bubble is between several meters and a few tens of meters, typical of a welldeveloped slug flow. The initial overpressure in the bubble is $\approx 10^{5} \mathrm{~Pa}$, much higher than previous estimates. This overpressure may arise from the coalescence of a foam layer at the top of the magma chamber or be generated by the influence of the air-magma interface on the approaching bubble. The radial velocities predicted by our model are comparable to independent measurements of both gas and ejecta. Since the thickness of the magma layer is constrained by observations of sizes of ejecta which vary in a narrow range, we believe that our predictions are robust. Measurements of acoustic pressure can therefore provide valuable informations on the physics of volcanic activity.

\section{Appendix A: Amplification by a Tube}

We discuss the amplification of the sound which can result of superimposing a tube full of air above the source. It is the case for the eastern vents, even if the lava is close to the surface [Vergniolle and Brandeis,
1994]. The vent can be viewed as a pipe of length $L$, containing a mixture of air and volcanic gas, driven at one side by a "piston", i.e., a bubble at the surface of magma, and with an open end at the other side. If the velocity at the closed end is $u$, at the open end it becomes

$$
v_{\circ}=\frac{u}{\cos (k L)}
$$

where $k$ is the wavenumber and $c$ is the sound speed [Landau and Lifshitz, 1987]. The amplification coefficient of the pipe $C$ is equal to

$$
C=\frac{1}{\cos ^{2}(k L)}
$$

Calculations show that during energetic oscillations of the main event, the velocity of the bubble cap is on the order of the velocity of gas and ejecta, showing that there is probably no significant amplification between the bubble cap and the exit of the volcanic conduit. Therefore the amplification coefficient $C$ is of the order of 1 .

\section{Appendix B: Sources of Damping}

Here we discuss the possible sources of damping for a bubble vibrating in a liquid. We evaluate the importance of each sources by measuring the ratio between the damping coefficient and the angular frequency of oscillations $\omega$. First, the bubble vibration can be damped by viscous forces of the magma. The viscous coefficient $\beta_{v}(12)$ is equal to

$$
\beta_{\mathrm{v}}=\frac{6 \mu}{\rho_{1} R_{\mathrm{eq}}^{2}}
$$

and is equal to 0.9 for a Strombolian magma with a viscosity of $400 \mathrm{~Pa}$ s. This is indeed small compared to the measured value of $\approx 60 \mathrm{rad} \mathrm{s}^{-1}$ for $\omega$.

Acoustic damping by radiation into the liquid finds its origin in the compressibility of liquid. For a spherical bubble with small oscillations, the coefficient of damping $\beta_{\mathrm{ac}}$ is equal to [Plesset and Prosperetti, 1977; Prosperetti, 1986]

$$
\beta_{\mathrm{ac}}=\frac{R_{\mathrm{eq}} \omega^{2}}{2 c_{\mathrm{l}}}
$$

where $c_{1}$ is the sound speed in magma slightly above to $2500 \mathrm{~m} \mathrm{~s}^{-1}$ [Rivers and Carmichael, 1987; Kress and Carmichael, 1991] for the shoshonite composition at Stromboli [Capaldi et al., 1978]. For radian frequencies around $60 \mathrm{rad} \mathrm{s}^{-1}$, as measured for Strombolian explosions, the damping coefficient $\beta_{\mathrm{ac}}$ is equal to 1 , again small compared to $\omega$.

Third is the thermal damping inside the gas. The coefficient of thermal damping $\beta_{\text {th }}$ for small oscillations [Prosperetti, 1986] depends on the thermal diffusivity of gas $\chi_{\mathrm{g}}$ and on the ratio of specific heat $\gamma$ 


$$
\beta_{\mathrm{th}}=\frac{9 \gamma(\gamma-1) p_{\mathrm{g} \mathrm{eq}}}{2 \rho_{\mathrm{l}} R_{\mathrm{eq}}^{3}}\left(\frac{\chi_{\mathrm{g}}}{2 \omega^{3}}\right)^{1 / 2}
$$

Taking a diffusivity equal to $8 \times 10^{-7} \mathrm{~m}^{2} \mathrm{~s}^{-1}$ [Sparks, 1978] and $\gamma$ equal to 1.1 for hot gases [Lighthill, 1978], we obtain a damping coefficient $\beta_{\mathrm{th}}$, equal to $7 \times 10^{-6}$ for a bubble of $1 \mathrm{~m}$, exceedingly small compared to $\omega$.

Finally, for a bubble close to solid walls, like a Strombolian bubble vibrating in a tube, damping by radiation of seismic waves into the ground is also possible. Measurements suggest that seismic waves are much less energetic than acoustic waves produced in air [Braun and Ripepe, 1993] and hence have been neglected in our model. In summary, among the different damping coefficients, the largest is the viscous damping.

Acknowledgments. We thank J.-C. Mareschal, J.-L. Cheminée, X. Hill, A. Davaille, A. Woods, V. Ferrazini, P. Allard, J. Déverchère, Y. Gaudemer, M.-F. Le Cloarec, F. Le Guern, D. Snyder, T. Trull. Thorough reviews by R. S. J. Sparks, M. J. Buckingham, and T. Koyaguchi greatly improved the manuscript. This work was supported by CNRSINSU-DBT Terre profonde and EEC grants SC1*CT005010 and EV5V-CT92-0189. This is IPGP Contribution 1441 and INSU-DBT contribution 764 .

\section{References}

Allard, P., J. Carbonelle, N. Metrich, and H. Loyer, Sulphur output and magma degassing budget of Stromboli volcano, Nature, 368, 326-330, 1994.

Avedik, F., V. Renard, J.-P. Allenou and B. Morvan, "Single-bubble" air-gun array for deep exploration, Geophysics, 58, 366-382, 1993.

Azbel, D., Two-Phase Flow in Chemical Engineering, 311 pp., Cambridge Univ. Press, New York, 1981.

Batchelor, G. K., An Introduction to Fluid Dynamics, 615 pp., Cambridge Univ. Press, New York, 1967.

Blackburn, E. A., L. Wilson, and R. S. J Sparks, Mechanics and dynamics of Strombolian activity, J. Geol. Soc. London, 132, 429-440, 1976.

Boulton-Stone, J. M., and J. R. Blake, Gas bubbles bursting at a free surface, J. Fluid Mech., 99, 9415-9422, 1993.

Braun, T., and M. Ripepe, Interaction of seismic and air waves recorded at Stromboli volcano, Geophys. Res. Lett., 20, 65-68, 1993.

Buckingham, M. J., and M. A. Garcés, Canonical model of volcano acoustics, J. Geophys. Res., 101, 8129-8151, 1996.

Butterworth, D., and G. Hewitt, Two-Phase Flow and Heat Transfer, 514 pp., Oxford Univ. Press, New York, 1977.

Capaldi, G., et al., Stromboli and its 1975 eruption, Bull. Volcanol., 41, 1-27, 1978.

Chandrasekhar, S., Hydrodynamic and Hydromagnetic Stability, 654 pp., Dover, New York, 1961.

Chouet, B., N. Hamisevicz, and T. R. McGetchin, Photoballistics of volcanic jet activity at Stromboli, Italy, J. Geophys. Res., 79, 4961-4975, 1974.

Cole, R. H., Underwater Explosions, 432 pp., Princeton Univ. Press, Princeton, N.J., 1948.

Davies, R. M., and G. I. Taylor, The mechanics of large bubbles rising through extended liquids and through liquids in tube, Proc. R. Soc. London A, 200, 375-390, 1950.

Drazin, P. G., Nonlinear Systems, 317 pp., Cambridge Univ. Press, New York, 1992.
Francalanci, L., P. Manetti, and A. Pecerillo, Volcanological and magmatological evolution of Stromboli volcano (Aeolian islands): The roles of fractional crystallization, magma mixing, crustal contamination and source heterogeneity, Bull. Volcanol., 51, 335-378, 1989.

Giberti, G., C. Jaupart, and G. Sartoris, Steady-state operation of Stromboli volcano, Italy: Constraints on the feeding system, Bull. Volcanol., 54, 535-541, 1992.

Jaupart, C., and S. Vergniolle, Dynamics of degassing at Kilauea volcano, Hawaii, Nature, 331, 58-60, 1988.

Jaupart, C., and S. Vergniolle, The generation and collapse of a foam layer at the roof of a basaltic magma chamber, J. Fluid Mechanics, 203, 347-380, 1989.

Kay, J. M., and R. M. Nedderman, Fluid Mechanics and Transfer Processes, 602 pp., Cambridge Univ. Press, New York, 1985.

Kress, V. C., and I. S. E. Carmichael, The compressibility of silicate liquids containing $\mathrm{Fe}_{2} \mathrm{O}^{3}$ and the effect of composition, temperature, oxygen fugacity, and pressure on their redox state, Contrib. Mineral. Petrol., 108, 82-92, 1991.

Landau, L. D., and E. M. Lifshitz, Course in Theoretical Physics: Fluids Mechanics, vol. 6, 536 pp., Pergamon, Tarrytown, N.Y., 1987.

Leighton, T. G., The Acoustic Bubble, 613 pp., Academic, San Diego, Calif.,1994.

Lighthill, J., Waves in Fluids, 504 pp., Cambridge Univ. Press, New York, 1978.

Longuet-Higghins, M., Bubble noise spectra, J. Acoust. Soc. Am., 87, 652-661, 1990.

Lu, N. Q., H. N. Oguz, and A. Prosperetti, The oscillations of a small floating bubble, Phys. Fluids A, 1, 252-260, 1989.

Pierce, A. D., Acoustics: An Introduction to its Physical Principles and Applications, 678 pp., McGraw-Hill, New York, 1981.

Plesset, M. S., and T. P. Mitchell, On the stability of the spherical shape of a vapor cavity in liquid, Quat. Appl. Math., 13, 419-430, 1956.

Plesset, M. S., and A. Prosperetti, Bubble dynamics and cavitation, Annu. Rev. Fluid Mech., 9, 145-185, 1977.

Prosperetti, A., Bubble dynamics, Proc. Int. School Phys. E. Fermi, 93, 145-188, 1986.

Richards, A. F., Volcanic sounds, investigation and analysis, J. Geophys. Res., 68, 919-928, 1963.

Ripepe, M., M. Rossi, and G. Saccarotti, Image processing of explosive activity at Stromboli, J. Volcanol. Geotherm. Res., 54, 335-351, 1993.

Rivers, M. L., and I. S. E. Carmichael, Ultrasonic studies of silicate melts, J. Geophys. Res., 92, 9247-9270, 1987.

Ryerson, F. J., H. C. Weed and A. J. Piwinskii, Rheology of subliquidus magmas, I, Picritic compositions, J. Geophys. Res., 93, 3421-3436, 1988.

Shaw, H. R., Rheology of basalt in the melting range, $J$. Petrol., 10, 510-535, 1969.

Shaw, H. R., Viscosities of magmatic silicate liquids: An empirical method of prediction, Am. J. Sci., 272, 870$893,1972$.

Sparks, R. S. J., The dynamics of bubble formation and growth in magmas: A review and an analysis, J. Volcanol. Geotherm. Res., 3, 1-37, 1978.

Spiel, D. E., Acoustical measurements of air bubbles bursting at a water surface: Bursting bubbles as Helmholtz resonators, J. Geophys. Res., 97, 11443-11452, 1992.

Taylor, G. I., The dynamics of thin sheet of fluids, II, Waves on fluid sheets, Proc. R. Soc. London A, 253, 289-312, 1959.

Taylor, G. I., The vertical motion of a spherical bubble and the pressure surrounding it, in The Scientific Papers of 
G.I. Taylor, vol. 3, pp. 320-336, Cambridge Univ. Press, New York, 1963.

Taylor, G. I., and R. M. Davies, The motion and shape of the hollow produced by an explosion in a liquid, in The Scientific Papers of G.I. Taylor, vol. 3, pp. 337-353, Cambridge Univ. Press, New York, 1963.

Thorpe, S. A., Bubbles and breaking waves, Nature, 283, 463-465, 1980.

van der Molen, I., and M. S. Paterson, Experimental deformation of partially melted granite, Contrib. Mineral. Petrol., 70, 299-318, 1979.

Vergniolle, S., and G. Brandeis, Origin of the sound generated by Strombolian explosions, Geophys. Res. Lett., 21, 1959-1962, 1994.

Vergniolle, S., and C. Jaupart, Separated two-phase flow and basaltic eruptions, J. Geophys. Res., 91, 12842-12860, 1986.

Vergniolle, S., and C. Jaupart, Dynamics of degassing at Kilauea volcano, Hawaii, J. Geophys. Res., 95, 2793-2809, 1990.

Vergniolle, S., G. Brandeis, and J.-C. Mareschal, Strombolian explosions, 2. Eruption dynamics determined from acoustic measurements, J. Geophys. Res., this issue.

Walker, D., and O. Mullins Jr., Surface tension of natural silicates from $1200-1500^{\circ} \mathrm{C}$ and implications for melt structure, Contrib. Mineral. Petrol., 76, 455-462, 1981.

Wallis, G. B., One Dimensional Two-Phase Flows, 408 pp., McGraw-Hill, New-York, 1969.
Webb, S. L., and D. B. Dingwell, Non-Newtonian rheology of igneous melt at high stresses and strain rates: Experimental results for rhyolite, andesite, basalt, and nepheline, J. Geophys. Res., 95, 15695-15701, 1990.

Weill, A., G. Brandeis, S. Vergniolle, F. Baudin, J. Bilbille, J.-F. Fèvre, B. Piron, and X. Hill, Acoustic sounder measurements of the vertical velocity of volcanic jets at Stromboli volcano, Geophys. Res. Lett., 19, 2357-2360, 1992.

Wilson, L., Relationships between pressure, volatile content and ejecta velocity, J. Volcanol. Geotherm. Res., 8, 297$313,1980$.

Woulff, G., and T. R. McGetchin, Acoustic noise from volcanoes: Theory and experiments, Geophys. J. R. Astron. Soc., 45, 601-616, 1976.

G. Brandeis, UMR 5562/CNRS, GRGS, Observatoire Midi-Pyrénées, 14 avenue Edouard-Belin, 31400 Toulouse, France. (e-mail: brandeis@pontos.cst.cnes.fr)

S. Vergniolle, Laboratoire de Dynamique des Systèmes Géologiques, Institut de Physique du Globe de Paris, 4 place Jussieu, 75252 Paris cedex 05, France. (e-mail: vergniol@ipgp.jussieu.fr)

(Received June 13, 1995; revised April 1, 1996; accepted April 9, 1996.) 